\title{
Estudo farmacobotânico das folhas de Tocoyena formosa (Cham. \& Schltdl.) K.Schum. (Rubiaceae)
}

\author{
Victor Peçanha de Miranda Coelho ${ }^{1}$, Maria de Fátima Agra ${ }^{1 *}$, \\ Maria Regina de Vasconcellos Barbosa ${ }^{2}$ \\ ${ }^{1}$ Laboratório de Tecnologia Farmacêutica, Universidade Federal da Paraíba, \\ Caixa Postal 5009, 58051-970, João Pessoa, PB, Brasil, \\ ${ }^{2}$ Departamento de Sistemática e Ecologia, Universidade Federal da Paraíba, \\ Caixa Postal 5065, 58051-970, João Pessoa, PB, Brasil
}

\begin{abstract}
RESUMO: Este trabalho teve como objetivo um estudo farmacobotânico das folhas de Tocoyena formosa (Cham. \& Schltdl.) K. Schum., espécie usada na medicina popular do Nordeste do Brasil no tratamento das dores reumáticas. Realizaram-se estudos morfológicos para a identificação da espécie e para a morfodiagnose macroscópica. Cortes paradérmicos e transversais do pecíolo e da lâmina foliar, à mão livre, foram corados com safranina ou com uma mistura de safranina e azul de astra para a morfodiagnose microscópica. A lâmina foliar é subcoriácea, oblongo-lanceolada a elíptica, densamente tomentosa na face abaxial. T. formosa possui folhas hipoestomáticas, com estômatos do tipo paracítico; epiderme unisseriada com células de paredes poligonais; mesofilo dorsiventral com idioblastos cristalíferos, esparsos, isolados ou aos pares, no estrato superior do parênquima paliçádico; tricomas simples são evidentes na epiderme, em ambas faces. A vascularização é formada por dois feixes assessórios na posição adaxial e um feixe central em arco com as terminações invaginadas, na porção proximal do pecíolo, ou em forma de "V-fechado" na porção distal e na nervura principal. A morfologia das estruturas vegetativas e reprodutivas associada à anatomia do mesofilo e do sistema vascular, em conjunto, são caracteres distintivos para esta espécie.
\end{abstract}

Unitermos: Tocoyena formosa, Rubiaceae, plantas medicinais, farmacobotânica.

\begin{abstract}
Pharmacobotanical study of the leaves of Tocoyena formosa (Cham. \& Schltdl.) K.Schum. (Rubiaceae)". This work constitutes a pharmacobotanical study of Tocoyena formosa (Cham. \& Schltdl.) K. Schum., a species used in folk medicine for rheumatic pains in Northeastern Brazil. The botanical identification and macroscopical morphodiagnosis were carried out by morphological studies. The microscopical morphodiagnosis were realized by paradermic and transversal cuts of the leaves (blades and petiole) and stained with safranin or mixture of safranin and astrablue. The blade leaf is subcoriaceous and oblong-lanceolate to elliptic, densely tomentose in the abaxial surface. T. formosa has hypostomatic leaves with stomata of the paracitic type; unisseriate epidermis with polygonal cells; the mesophyll is dorsiventral and the parenchyma palisade has sparse idioblasts crystallifer, isolated or paired; trichomes simple were evident in the epidermis of both faces. The vascular system was formed by two accessories bundles in the adaxial surface and by one central vascular bundle in arc with invaginate extremities on the proximal portion of petiole, and in shape of "V-closed" on distal portion of the petiole and main vein. The vegetative and reproductive morphologies associate to the anatomy of mesophyll and vascular system constitute a set of characters distinctive for this species.
\end{abstract}

Keywords: Tocoyena formosa, Rubiaceae, medicinal plants, pharmacobotany.

\section{INTRODUÇÃO}

A família Rubiaceae é a maior da ordem Gentianales, com cerca de 650 gêneros e 13.000 espécies (Rova et al., 2002), que corresponde a $66 \%$ do total das Gentianales (Struwe, 2002). Entretanto, a subdivisão da família tem variado de autor para autor (Verdcourt, 1958; Bremekamp, 1966; Robbrecht, 1988). Estudos filogenéticos mais recentes propõem a divisão de Rubiaceae em três subfamílias: Rubioideae, Cinchonoideae e Ixoroideae (Bremer, 1996; Bremer et al., 1999).
Rubiaceae possuiespécies degrandeimportância econômica, que são exploradas como alimentícias (Coffea arabica L. e Genipa americana L.), ornamentais (Ixora spp., Mussaenda spp., Gardenia spp. etc.), e também na indústria farmacêutica, como por exemplo Cinchona pubescens Vahl, produtora de quinina, empregada no tratamento da malária. Além disso, várias espécies são referidas popularmente como medicinais e/ou tóxicas, dentre as quais destacam-se: Coutarea hexandra (Jacq.) K.Schum. e diversas espécies dos gêneros Borreria, Cinchona, Richardia, como medicinais; Palicourea e Psychotria, popularmente conhecidas como "mata-ratos", 


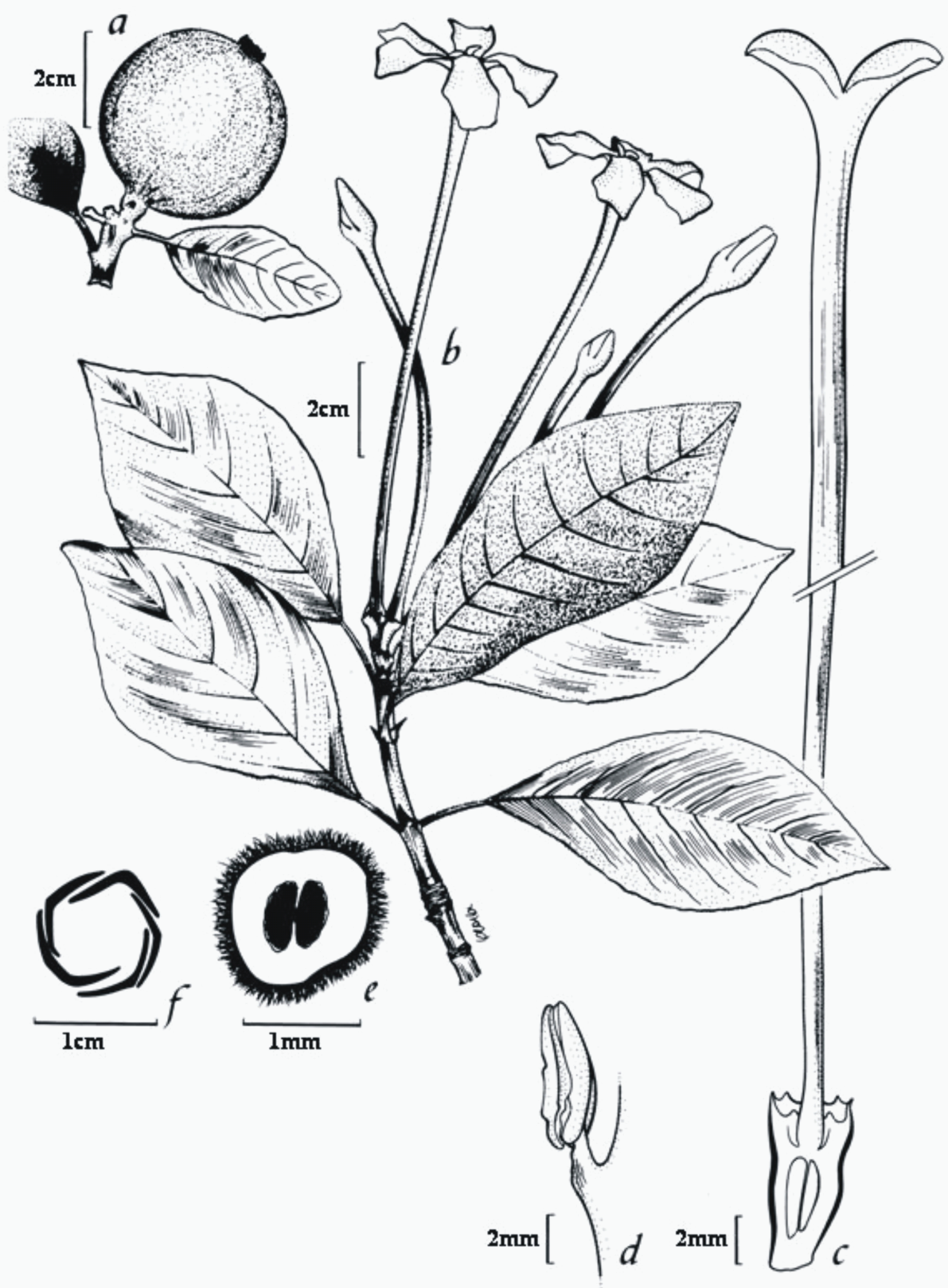

Figura 1. Tocoyena formosa (Cham. \& Schltdl.) K. Schum. (Agra et al. 6127). a. baga; b. ramo florido; c. gineceu e hipanto, em secção longitudinal, com detalhe ampliado do estigma lamelar; d. estame em visão lateral; e. ovário, em secção transversal; f. representação esquemática da prefloração.

que são consideradas venenosas.

De acordo com Struwe et al. (1994), Struwe (2002) e Schripsema et al. (2003), quimicamente, a família destaca-se pela presença de alcalóides quinolínicos (quinina e cinchonina), isoquinolínicos (emetina), indólicos (iombina) e bases de purina como a cafeína, substância utilizada na indústria farmacêutica e alimentícia de todo mundo.
O gênero Tocoyena Aublet possui cerca de 30 espécies com distribuição neotropical, ocorrendo na América Central e América do Sul, até sul do Brasil, tendo como seu principal centro de diversidade a região Amazônica (Gottsberger; Ehrendorfer, 1992). Tocoyena formosa (Cham. \& Schltdl.) K.Schum. é uma espécie sul-americana, encontrada no Paraguai, Bolívia e Brasil, principalmente em formações xeromórficas 
como cerrado, restinga e caatinga. No Brasil, a espécie possui ampla distribuição ocorrendo nas regiões Norte, Nordeste, Centro-Oeste, Sudeste e Sul até o estado do Paraná (Prado, 1987; Gottsberger; Ehrendorfer, 1992).

O presente trabalho teve como objetivo realizar um estudo farmacobotânico das folhas de Tocoyena formosa (Cham. \& Schltdl.) K.Schum., espécie cujos iridóides isolados da planta apresentaram atividade antifúngica (Bolzani et al., 1996, 1997). Embora esta seja uma espécie reconhecida por sua importância na medicina popular e com potencial emprego na farmacologia, as informações sobre sua farmacobotânica e anatomia foliar são inexistentes.

\section{MATERIAL E MÉTODOS}

\section{Coletas e identificações botânicas}

Coletas botânicas e observações de campo foram realizadas para a identificação, estudos morfológicos e anatômicos. Parte das amostras foi herborizada, seguindose a metodologia descrita em Forman e Bridson (1989) e posteriormente depositadas no Herbário Lauro Pires Xavier (JPB), com duplicatas na coleção de referência do Laboratório de Tecnologia Farmacêutica (LTF). Outra parte das amostras foi conservada em álcool a $70^{\circ}$. A identificação botânica e os estudos morfológicos foram realizados com a análise de amostras frescas, conservadas e exsicatas do herbário JPB, com auxílio da bibliografia (Müller-Argovensis, 1881; Prado, 1987; Gottsberger; Ehrendorfer, 1992). As morfodiagnoses macroscópicas e as ilustrações foram realizadas com auxílio de estereomicroscópio binocular com câmara-clara, Zeiss. As abreviaturas dos autores dos táxons estão de acordo com Brummitt e Powell (1992).

\section{Estudos anatômicos}

Foram realizados cortes paradérmicos nas faces adaxial e abaxial da lâmina foliar, à mão livre. Os cortes transversais foram efetuados no $1 / 3$ mediano da lâmina e nas partes distal, mediana e proximal do pecíolo, com auxílio de lâmina cortante, em amostras frescas, conservadas em álcool $70^{\circ}$ e secas submetidas a amolecimento após fervura, incluídas na medula do pecíolo de Cecropia sp. Os cortes foram clarificados com hipoclorito de sódio a $50 \%$ e corados com safranina ou mistura de safranina e azul de astra, montados entre lâmina e lamínula com glicerina a $50 \%$. Os cristais de oxalato de cálcio foram reconhecidos pelo teste de solubilidade em ácido clorídrico a 10\% (Chamberlain, 1932). As fotomicrografias foram realizadas ao microscópio ótico, Olympus CH30, com câmara fotográfica Olympus PMBP35. Para a classificação dos estômatos, caracterização das paredes celulares, mesofilo e dos tricomas baseou-se em Metcalf e Chalk (1979).
Informações etnomedicinais, químicas e atividades biológicas

Os dados etnomedicinais foram obtidos através de pesquisa em várias fontes: informações de mateiros, raizeiros, vendedores de plantas medicinais; etiquetas das exsicatas do herbário JPB; e na literatura. As informações dos constituintes químicos e atividades biológicas foram obtidas através da pesquisa bibliográfica e do banco de dados Natural Products Alert (NAPRALERT).

\section{RESULTADOS}

Tocoyena formosa (Cham. \& Schltdl.) K. Schum., in Mart Fl. Bras. 6(6): 347. 1889.

Sinônimos: Gardenia formosa Cham. \& Schltdl., Linnaea 4: 200. 1829; Tocoyena microdon Mart., Flora 24 Beibl. 2 (6): 82. 1841; Tocoyena velutina Mart., Flora 24 Beibl. 2 (6): 81. 1841; Tocoyena formosa var. maxima Chod. \& Hassl., Bull. Herb. Boiss. 4: 326. 1904; Tocoyena bullata var. speciosa f. puberula Chod. \& Hassl., Bull. Herb. Boiss. 4: 326. 1904; Tocoyena formosa var. petropolitana Glaz., Mem. Soc. Bot., France. 3: 343. 1905; Tocoyena sprucei Standl., Field. Mus. of Nat. History, 8 (5): 350-351. 1931; Tocoyena surinamensis Bremek., Mede. Bot. Mus. Herb. Rijts Univ. Utrech. 33 (35): 710-711. 1936; Tocoyena puberula Spruce nomen nudum; Tocoyena brasiliensis Auct. non Mart. nomen nudum (Prado, 1987).

Nomes vernaculares: BRASIL: genipa-brava, trombeta, genipaparaná, pau-de-cera, genipapo, genipapobrabo, marmelada-brava, genipapo-bravo, genipapeirobravo, geniparana, genipapo-de-cavalo, figo-de-guará, genipapim, pau-de-cachimbo, genipapinho, genipapodo-campo, goiaba-brava (Prado, 1987).

Descrição morfológica: Arbusto ou arvoreta, 2,0-4,5 m alt. Ramos cilíndricos, branco-acinzentados, castanhos, espessos, parcialmente estriados e glabros. Estípulas caducas $0,3-0,6$ × 0,3-0,4 cm, deltóides a triangular-lanceoladas, glabras ou pubérulas, castanhoferrugíneas. Folhas simples, opostas, verde-amareladas, lâmina $6,3-10,5 \times 3,0-4,5 \mathrm{~cm}$, oblongo-lanceolada a elíptica, subcoriácea, ápice agudo a levemente agudo, base aguda, obtusa nas folhas jovens, margem inteira, pubérula na face superior e denso-tomentosa na face inferior. Pecíolo 0,9-1,6 x 0,1-0,2 cm, cilíndrico, castanho amarelado, tomentoso. Inflorescência em dicásios compostos terminais. Botões florais retos de ápice obtuso a curto-acuminado, 1,1-2,0 x 0,6-1,0 cm. Cálice campanulado, persistente, 5 dentes, cálice + hipanto $0,6-1,0 \times 0,3-0,5 \mathrm{~cm}$, pubérulo. Corola amarela, hipocrateriforme, 5 lobos, tubo $8-10 \times 0,3-0,5 \mathrm{~cm}$, pilosa externamente e internamente apenas na fauce. Estames 5 , exsertos, presos à fauce, anteras subsésseis ca. $0,6 \mathrm{~cm}$, dorsifixas, glabras. Ovário ínfero, bilocular, pluriovulado; estilete cilíndrico, glabro; estigma exserto, bífido, lobos 

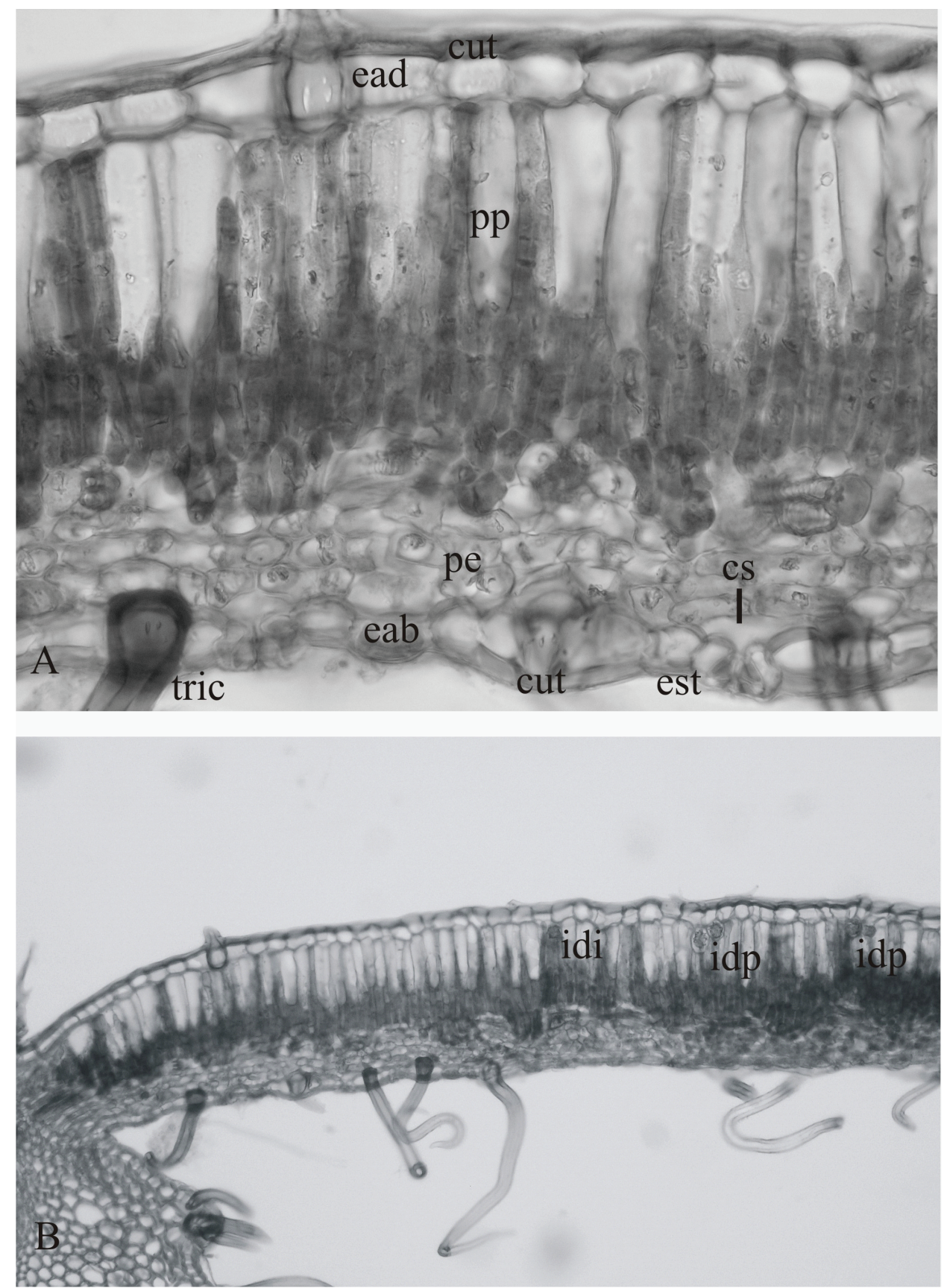

Figura 2. Tocoyena formosa (Cham. \& Schltdl.) K. Schum. (Agra et al. 6127). A. Seção transversal da lâmina foliar (400x): cutícula (cut); epiderme adaxial (ead); parênquima paliçádico (pp); parenquima esponjoso (pe); câmara sub-estomática (cs); epiderme abaxial (eab); tricoma (tric); estômato (est). B. Aspecto geral do mesofilo em seção transversal (100x): idioblasto isolado (idi); idioblasto pareado (idp).

oblongos. Fruto baga globosa a sub-globosa, estriada, pilosa quando jovem, $5,0 \times 4,0 \mathrm{~cm}$ (Fig. 1).

Descrição anatômica: A lâmina foliar na face adaxial, em secção transversal, apresenta uma cutícula lisa e espessa revestindo as paredes periclinais externas da epiderme, que é unisseriada, com células de tamanhos irregulares, quadrangulares ou arredondadas. Os tricomas são simples, 1-3-celulares, unisseriados, com paredes lisas e espessadas, eretos ou recurvos (Fig. 2A,B), semelhantes ao tipo descrito como "hair sclereids" por Guédès (1975) e Metcalfe e Chalk (1979). Em vista frontal, a epiderme apresenta células poligonais, possuindo 4-6 lados, com paredes anticlinais retas a levemente sinuosas, onde os tricomas são evidentes, circundados por 4-7 células (Fig. $3 \mathrm{~A})$.

$$
\text { O mesofilo é heterogêneo, com estrutura }
$$
dorsiventral, apresentando parênquima paliçádico com 2-4 estratos, sendo o superior cerca de três vezes maior. 

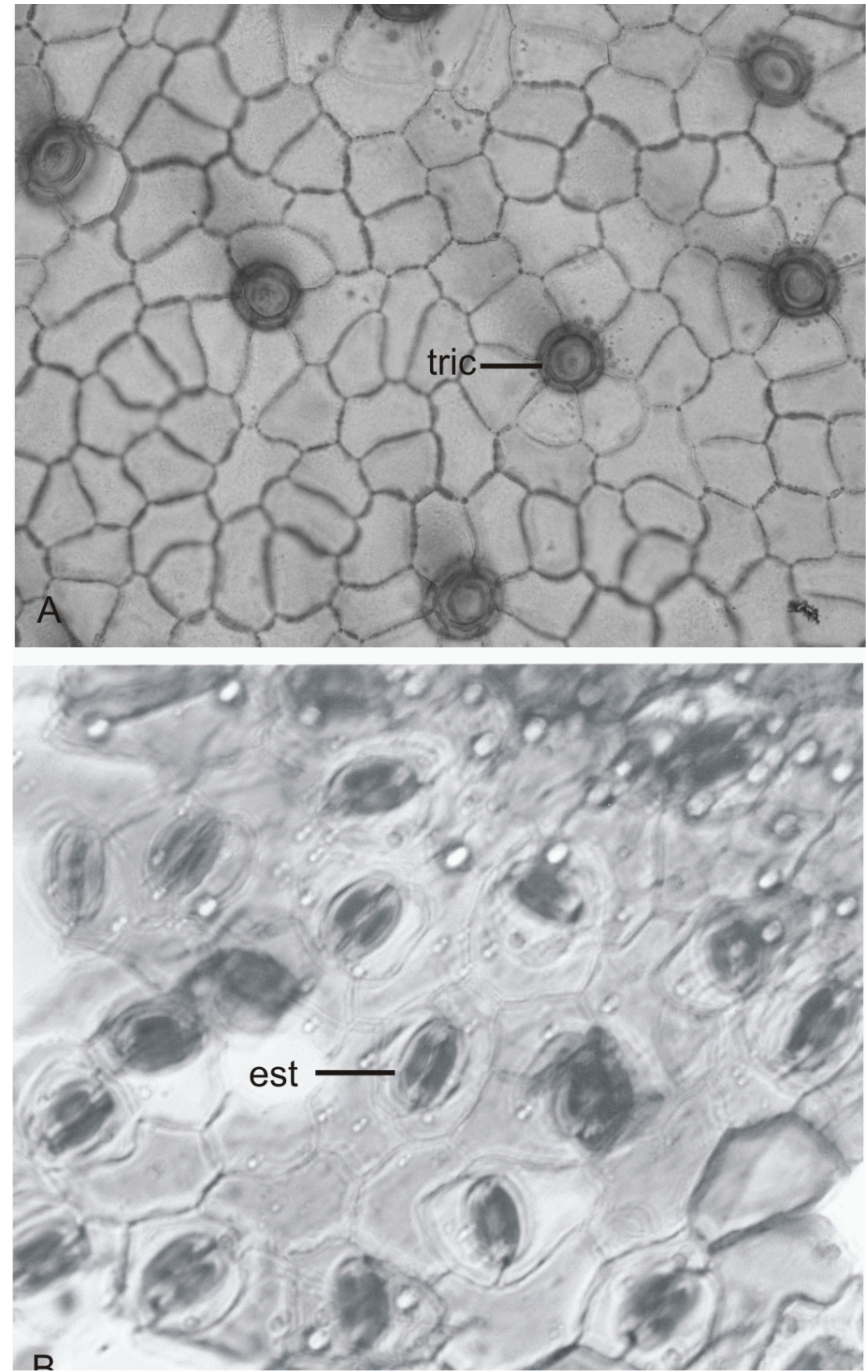

Figura 3. Tocoyena formosa (Cham. \& Schltdl.) K. Schum. (Agra et al. 6127). A-B. Epiderme, em vista frontal (400x): A. Face adaxial, paredes celulares poligonais, retas. B. Face abaxial, paredes celulares retas a sinuosas, com estômatos paracíticos.

O parênquima esponjoso também possui um número variável de estratos, com células de tamanhos variados e espaços irregulares (Fig. 2A). Numerosos idioblastos cristalíferos contendo drusas de oxalato de cálcio foram observados no estrato superior do parênquima paliçádico, adjacente à epiderme, dispostos isoladamente ou aos pares, lado a lado (Fig 2B).

A nervura principal da lâmina foliar em $T$. formosa é biconvexa, sendo mais proeminente na face abaxial. Em corte transversal, a epiderme é unisseriada, com células arredondadas, revestidas por uma cutícula lisa e delgada nas paredes periclinais externas. Adjacente à epiderme, nota-se o colênquima do tipo angular, com três a quatro séries contínuas de células. O parênquima cortical possui células ovais e circulares, maiores e com paredes mais delgadas que as do colênquima. O sistema vascular é colateral, formado por um feixe central, em forma de "V" fechado, medulado, constituído por cinco a seis séries de células xilemáticas e várias séries de células de floema, externamente. Dois feixes circulares 

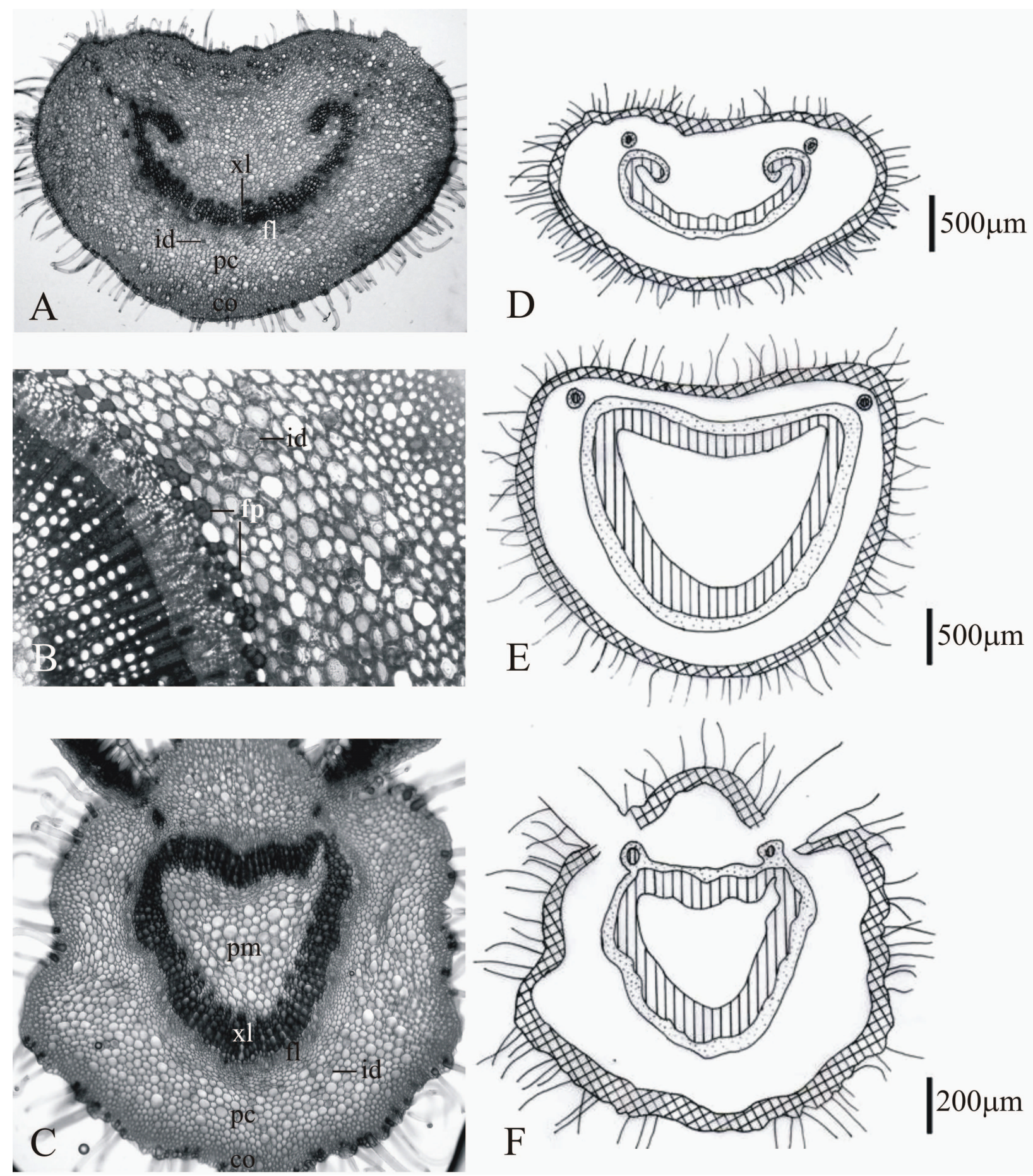

Figura 4. (A-F) Tocoyena formosa (Cham. \& Schltdl.) K. Schum. (Agra et al. 6127). A-C. Seção transversal do pecíolo e nervura principal: A. vascularização com um feixe central, em arco, e dois feixes laterais (100x); B. Detalhe do feixe central (40x); C. Nervura principal, feixe vascular em "V" fechado (100x). D-F. Esquema da vascularização do pecíolo e nervura principal: D. região proximal do pecíolo, feixe central aberto; E. região mediana, feixe central fechado; F. nervura principal. Legendas: $\mathbf{c o}=$ colênquima, $\mathbf{p c}=$ parênquima cortical, $\mathbf{i d}=$ idioblasto, $\mathbf{f l}=$ floema, $\mathbf{x l}=$ xilema, $\mathbf{p m}=$ parênquima medular, $\mathbf{f p}=$ fibras perivasculares.

menores acompanham o feixe central na face adaxial. O parênquima medular apresenta células de formato mais arredondado do que as do córtex. Observou-se a presença de idioblastos cristalíferos, contendo drusas de oxalato de cálcio, distribuídos irregularmente nos parênquimas cortical e medular (Fig. 4C,F).

$\mathrm{Na}$ face abaxial, em vista frontal, a epiderme possui células poligonais com paredes anticlinais retas a levemente sinuosas, similar à epiderme na face adaxial, e estômatos do tipo paracítico (Fig. 3B). Em secção 
transversal, a epiderme unisseriada possui células menores cujas paredes periclinais externas são revestidas por uma cutícula lisa e menos espessa do que na face adaxial. Os estômatos são observados no mesmo nível das demais células epidérmicas, evidenciando-se a presença da câmara sub-estomática. Os tricomas são similares aos da face adaxial, porém são maiores, 2-10-celulares, sinuosos ou recurvos e em maior densidade (Fig. 2A,B).

O pecíolo, em secção transversal, possui contorno levemente arqueado cujo diâmetro diminui em direção a lâmina foliar. A epiderme é unisseriada e revestida por uma cutícula lisa e delgada nas paredes periclinais externas, com tricomas 2-6-celulares, recurvos, similares aos da lâmina foliar. $\mathrm{O}$ colênquima é do tipo angular, apresentando-se em faixas contínuas de 8-10 séries de células. O parênquima cortical possui células ovais e circulares maiores e de paredes mais delgadas do que as do colênquima (Fig. 4A). Externamente ao floema, observa-se a presença de fibras perivasculares (Fig. 4B). Uma grande quantidade de idioblastos cristalíferos, contendo drusas de oxalato de cálcio, foi observada em ambos parênquimas (Fig. 4A,B). O sistema vascular é do tipo colateral, formado por um feixe central, em arco com as extremidades invaginadas, acompanhado por dois feixes assessórios na posição adaxial, circulares e menores. Ao longo do pecíolo estas extremidades vão se fechando gradualmente em direção à lâmina formando um feixe vascular medulado, em forma de "V", condição que permanece na nervura principal (Fig. 4A,D,E,F).

Material examinado: BRASIL. Paraíba: Município de Serra Branca, 20 Fev. 2002, M.R. Barbosa et al. 2205 (JPB); 04 Mai. 2004, Agra et al. 6127 (JPB); Município de São José dos Cordeiros, 24 Jan. 2003, Z. Quirino et al. 16 (JPB); 23 Mar. 2003, I.B. Lima et al. 90 (JPB).

Etnomedicina: Registrou-se o uso tópico das folhas frescas e maceradas para o tratamento das dores reumáticas.

Constituintes químicos: Foram isolados das folhas e caule de $T$. formosa doze constituintes químicos. Saponina triterpênica: ácido 3-O- $\beta$-D-glicopiranosil-28O- $\beta$-D-glicopiranosil-quinóvico; flavonóide: 3-O- $\beta$-Dramnosil-3-O-metilquercetina; iridóides: apodantosídeo, galiosídeo, formosinosídeo, ferulato de 11-O-transteucreína, $\alpha$ e $\beta$ - gardiol, mologosídeo-metil-éster (Bolzani et al., 1996, 1997) e genipina; esteróide: estigmasterol; fenilpropanóide: éster etílico do ácido ferúlico (Ribeiro; Cunha, 2004).

Atividades biológicas: Um estudo realizado com a casca da raiz registrou forte atividade estimulante em útero de ratas (Barros et al., 1970). Estudos realizados por Bolzani et al. $(1996,1997)$ com os iridóides (ferulato de 11-O-trans-teucreína e $\alpha$ e $\beta$-gardiol) isolados dos ramos e folhas, apresentaram atividade antifúngica contra Cladosporium cladosporioides.

\section{DISCUSSÃO E CONCLUSÕES}

Tocoyena formosa é uma espécie que apresenta grande plasticidade na morfologia foliar, variando de oblongo-lanceolada a elíptica. Entretanto, do ponto de vista morfológico, a espécie caracteriza-se por apresentar a lâmina foliar subcoriácea a coriácea, com a venação impressa na face adaxial e proeminente na abaxial, densamente tomentosa e macia ao tato.

Estômatos do tipo paracítico e epiderme com células poligonais de paredes anticlinais retas constituem um caráter comum às espécies da família Rubiaceae (Solereder, 1908; Vieira, 1986/88; Vieira et al., 1992; Pereira et al., 2003; Alves et al. 2004; Kocsis et al., 2004). Os tricomas são uni a pluricelulares, intrusivos, similares aos "hairs sclereids" de Metcalfe e Chalk (1979), descritos pela primeira vez por Guédès (1975) para o gênero Jovetia (Rubiaceae), também observados por Vieira (1986/88) em Tocoyena bullata. O mesofilo dorsiventral de Tocoyena formosa com o número variável de estratos dos parênquimas paliçádico e esponjoso, coincide com o de T. bullata (Vieira, 1986/88) e de outros gêneros de Rubiaceae, como Psychotria (Vieira et al., 1992), Rudgea (Alves et al. 2004) e Rondeletia (Kocsis et al., 2004).

A vascularização do pecíolo em Tocoyena formosa é do tipo colateral, constituída de um feixe central, em arco ou em forma de "V" e dois feixes assessórios. Entretanto, esta espécie não possui feixes medulares, como os descritos para T. bullata por Vieira (1986/88). A ausência de floema interno é um caráter também observado em T. bullata por Vieira (1986/88) e em outros gêneros de Rubiaceae (Vieira, 1986; Vieira et al., 1992; Assis; Giulietti, 1999; Pereira et al., 2003; Alves et al., 2004; Kocsis et al., 2004).

A presença de idioblastos cristalíferos, do tipo drusas, foi referida para o gênero Tocoyena por Solereder (1908) e mais recentemente para T. bullata por Vieira (1986/88). Este tipo de idioblasto também foi referido para Diodia radula (Vieira, 1986). No entanto, idioblastos do tipo drusa, cuja localização interrompe o estrato superior do parênquima paliçádico, observados em Tocoyena formosa, foram registrados também para Tocoyena bullata (Vieira, 1986/88). Nestas duas espécies de Tocoyena os idioblastos cristalíferos estão dispostos isoladamente ou aos pares. Entretanto em T. formosa os idioblastos pareados, dispõem-se lado a lado, distinguindose de T. bullata cujos idioblastos pareados estão dispostos um sobre o outro, com base nas observações de Vieira $(1986 / 88)$.

Os tecidos de sustentação, colênquima angular e fibras perivasculares, observados em $T$. formosa coincidem com os já registrados para a família (Vieira, 1986, 1986/88; Vieira et al., 1992; Assis; Giulietti, 1999; Pereira et al., 2003; Alves et al., 2004; Kocsis et al., 2004).

A atividade antiinflamatória da genipina, iridóide isolado das folhas de Gardenia sp. (Koo et al., 2004) e

Rev. Bras. Farmacogn. Braz J. Pharmacogn. 16(2):abr/jun. 2006 
também de T. formosa (Ribeiro; Cunha, 2004), pode estar relacionada ao seu uso como anti-reumático na medicina popular. Entretanto, estudos químicos e farmacológicos adicionais são necessários para comprovar as atividades de T. formosa.

\section{AGRADECIMENTOS}

Ao CNPq pelas bolsas concedidas aos autores; José Maria Barbosa Filho, Diretor de Pesquisa do Laboratório de Tecnologia Farmacêutica Prof. Delby Fernandes de Medeiros, pelo apoio pessoal e institucional; George Sidney Baracho, pela ilustração; Dr. Jnanabrata Bhattacharyya pela revisão do Abstract; aos revisores da RBF e Kiriaki Nurit pelas valiosas sugestões; ao NAPRALERT pelo acesso ao banco de dados; Dulce G. Oliveira pelo apoio técnico. Este projeto teve o apoio financeiro do PELD-CNPq.

\section{REFERÊNCIAS}

Alves RMS, Stehmann JR, Isaías RMS, Brandão MGL 2004. Caracterização botânica e química de Rudgea viburnoides (Cham.) Benth., (Rubiaceae). Rev Bras Farmacogn 14: 49-56.

Assis MC, Giulietti AM 1999. Diferenciação morfológica e anatômica em populações de "ipecacunha" Psychotria ipecacunha (Brot.) Stokes (Rubiaceae). Rev Bras Bot 22: 205-216.

Barros GSG, Matos FJA, Vieira JEV, Sousa MP, Medeiros MC 1970. Pharmacological screening of some brazilian plants. J Pharm Pharmacol 22: 116.

Bolzani VDS, Trevisan LMV, Izumisawa CM, Young MCM 1996. Antifungal iridoids from the stems of Tocoyena formosa. J Braz Chem Soc 7: 157-160.

Bolzani VDS, Izumisawa CM, Young MCM, Trevisan LMV, Kingston DGI, Gunatilaka AL 1997. Iridoids from Tocoyena formosa. Phytochemistry 46: 305-308.

Bremekamp CEB 1966. Remarks on the position the delimitation and the subdivision of the Rubiacaea. Acta Bot Neerl 15: 1-33.

Bremer B 1996. Phylogenetic studies within Rubiaceae and relationships to other families based on molecular data Opera Bot Belg 7: 33-50.

Bremer B, Jansen RK, Oxelman B, Backlund M, Lantz H, Kim KJ 1999. More characters and more taxa for a robust phylogeny - case study from the coffee family (Rubiaceae). Syst Biol 48: 413-435.

Brummitt RK, Powel CE 1992. Authors of plant names. Royal Botanic Gardens: Kew Great Britanic.

Chamberlain C J 1932. Methods in plant histology. Chicago: The University of Chicago Press.

Forman L, Bridson D 1989. The herbarium handbook. Royal Botanic Gardens: Kew Great Britanic.

Gottsberger G, Ehrendorfer F 1992. Hybrid speciation and radiation in the neotropical woody genus Tocoyena (Rubiaceae). Plant Syst Evol 181: 143-169.

Guédès M 1975. Intrusive hair sclereids in Jovetia (Rubiaceae). Bot J Linn Soc 71: 141-144.

Kocsis M, Darók J, Borhidi A 2004. Comparative leaf anatomy and morphology of some neotropical Rondeletia
(Rubiaceae) species. Plant Syst Evol 248: 205-218.

Koo HJ, Song YS, Kim HJ, Lee YH, Hong SM, Kim SJ, Kim BC, Jin C, Lim CJ, Park EH 2004. Antiinflammatory effects of genipin, an active principle of ardenia. Eur J Pharmacol 495: 201-208.

Metcalfe CR, Chalk L 1979. Anatomy of the dicotyledons. Oxford: Oxford University Press.

Müller-Argovensis AJ 1881. Rubiaceae. In: Martius, C.F.P. (org.) Flora Brasiliensis 6: 1-470.

Pereira ZV, Meira RMSA, Azevedo AA 2003. Morfoanatomia foliar de Palicourea longepedunculata Gardiner (Rubiaceae). Rev Árvore 27: 759-767.

Prado AL 1987. Revisão taxonômica do gênero Tocoyena Aubl. (Rubiaceae) no Brasil. Campinas, 193p. Dissertação de Mestrado - Programa de Pós Graduação em Biologia Vegetal, Universidade Estadual de Campinas.

Ribeiro SG, Cunha EVL 2004. Estudo químico de Tocoyena formosa. XII Encontro de Iniciação Cientifica da Universidade Federal da Paraiba. João Pessoa, Brasil.

Robbrecht E 1988. Tropical wood Rubiaceae. Opera Bot Belg 1: 1-271.

Rova JHE, Delprete PG, Andersson L, Albert VA 2002. A trnLF cpDNA sequence study of the CondamineeaeRondeletieae-Sipaneeae complex with implications on the phylogeny of the Rubiaceae. Amer J Bot 89: 145-159.

Schripsema J, Dagnino D, Gosmann G 2003. Alcalóides indólicos. In: Simões CMO, Schenkel EP, Gosmann G, Mello JCP, Mentz LA, Petrovick PR (org.) Farmacognosia: da planta ao medicamento. 2.ed. Porto Alegre: Editora da Universidade UFRGS; Florianópolis: Editora da UFSC, p.679-705.

Solereder H 1908. Systematische Anatomie der Dicotyledone. Stuttgart: Ein Handbuch für Laboratorien der wissenchaftlichen und angewandten Botanik (Ergänzungsband). Ferdinand Enke.

Struwe L, Albert VA, Bremer B 1994. Cladistics and familylevel classification of the Gentianales. Cladistics 10: 175-206.

Struwe L 2002. Gentianales (Coffees, Dogbanes, Gentians and Milkweeds). Encyclopedia of life sciences, Macmillan publishers, Nature publishing group. disponível em: http://www.rci.rutgers.edu/ struwe/gentnet/reffiles/St ruwe $\% 202002 \% 20$ ELS $\% 20$ Gentianales.pdf, acessada em fevereiro de 2004

Verdcourt B 1958. Remarks on the classification of Rubiaceae. Bull Jard Bot l'Etat Bruxelles 28: 209-281.

Vieira RC 1986. Diodia radula (Willd. Et Hoffm.) Cham. Et Schlecht. (Rubiaceae) anatomia foliar. Rev Bras Biol 46: 667-674.

Vieira RC 1986/88. Tocoyena bullata (Vell.) Mart. (Rubiaceae) anatomia foliar. Rodriguésia 64/66: 33-39.

Vieira RC, Gomes DMS, Ferraz CLA 1992. Anatomia foliar de Psychotria nuda Wawra e Psychotria leiocarpa Mart. (Rubiaceae). Hoehnea 19: 185-195. 